\title{
A cultura das figurinhas: \\ as configurações de linguagens do colecionismo no álbum da Copa do Mundo FIFA 2018
}

\author{
The Culture of Stickers: \\ Study about the Configuration of Languages of Collecting in the \\ Album of the Sports Mega-event FIFA World Cup 2018
}

\author{
Anderson Gurgel Campos \\ Universidade Presbiteriana Mackenzie, São Paulo/Brasil \\ Doutor em Comunicação e Semiótica, PUC-SP \\ andersongurgel@hotmail.com
}

Helena Maria Afonso Jacob

Faculdade Cásper Líbero, São Paulo/Brasil Doutora em Comunicação e Semiótica, PUC-SP

Resumo: Desde 1970, o lançamento do álbum de figurinhas oficial da Copa do Mundo FIFA é um dos momentos mais esperados pelos fãs no período de preparação para esse megaevento esportivo. Para muitos, o Mundial de Futebol começa quando a febre das figurinhas toma escolas, parques, festas e conversas de botequim. Neste artigo estudamos o fenômeno do colecionismo no álbum da Copa do Mundo da Rússia 2018, sob o ponto de vista dos significados tanto deste objeto como das relações que os fãs desenvolvem com as figurinhas e com o álbum. 0 referencial teórico para a análise é a semiótica da cultura, de Iúri Lotman, além de aspectos centrais das teorias do jogo e dos megaeventos esportivos. 0 objetivo é contribuir para melhor entendimento da Copa do Mundo como texto da cultura e para a reflexão sobre as práticas realizadas nesse evento e seus impactos no público apaixonado por futebol.

Palavras-chave: Álbum de figurinhas; Copa do Mundo da FIFA Rússia 2018; Colecionismo; Semiótica da cultura; Megaeventos esportivos.

Abstract: Since 1970, the official FIFA World Cup sticker album has been released as one of the most anticipated moments for fans in the run-up to this sports mega-event. For many, the World Cup starts when the fever of the stickers takes schools, parks, parties and bars. In this article we study the phenomenon of collectivism in the Russian World Cup 2018 sticker album, from the point of view of the meanings of both this object and the relationships that fans develop with the figurines and the album. The theoretical reference for the analysis is the semiotics of culture, by Iúri Lotman, as well as central aspects of game theories and sports mega-events. The objective is to contribute to a better understanding of the FIFA World Cup as a text of the culture and to the reflection on the practices carried out in this event and its impact on the public in love with football.

Keywords: Sticker Album; FIFA World Cup Russia 2018; Collecting; Semiotics of Culture; Sports Mega-events. 


\section{INTRODUÇÃO: O ÁLBUM E O JOGO}

A cada quatro anos o mundo se volta para a Copa do Mundo FIFA e se lembra de que a principal competição do futebol masculino é mais que esporte; muito antes das disputas futebolísticas, traz consigo uma série de outros eventos, rituais e práticas de consumo. Desde 1930 esse megaevento esportivo capta atenções a nível planetário e, a cada edição, isso se torna mais intenso, graças ao mundo contemporâneo midiatizado, no qual uma atividade como essa é transmitido em diversas plataformas, especialmente as digitais.

O Mundial de Futebol explicita o fato de que esse esporte não é mais apenas esporte, mas um sistema cultural, no sentido dado por Iúri Lotman (1996), que gera linguagens, textos, produtos, estratégias comunicativas e muitas outras questões da ordem da cultura humana. Neste sistema, o futebol interage nas fronteiras com outros sistemas, tais como o consumo e o entretenimento, gerando produtos híbridos, caso do álbum de figurinhas da Copa do Mundo da Editora Panini, que alia estratégias de comunicação, esporte e colecionismo, gerando uma linguagem complexa e híbrida entre tantos sistemas.

O foco desta comunicação é o fenômeno daquilo que podemos chamar de "jogo dentro do jogo": a tradição do álbum de figurinhas da Copa, produto comercial exclusivo da editora italiana Panini há quase cinco décadas, que configura o jogo de colecionar dentro dos jogos de futebol do Mundial da FIFA, possibilitando que se jogue o jogo de completar o álbum antes do objeto cultural que o originou, a competição esportiva.

Desde o Mundial de Futebol de 1970, o álbum de cromos é lançado sempre antes do megaevento, sendo um momento, em geral, muito aguardado tanto pelos fãs do futebol quanto pelos fãs da Copa do Mundo. 0 álbum, veículo de consumo midiatizado e espetacular, afeta todo tipo de público, até mesmo aqueles que não ligam nem para o futebol e nem para o evento, mas que querem estar inseridos no acontecimento midiático do momento - no caso, a Copa.

Naquele que podemos chamar de "ciclo Copa" - período que engloba a preparação do país-sede do evento, as notícias sobre a convocação das seleções e a realização da competição em si -, um dos fatores que gera expectativa nos fãs é o começo da venda do álbum e da circulação das figurinhas que representam jogadores, equipes, escudos e estádios. 0 jogo já começa nesta expectativa: será que as seleções publicadas serão as escaladas para o mundial? 


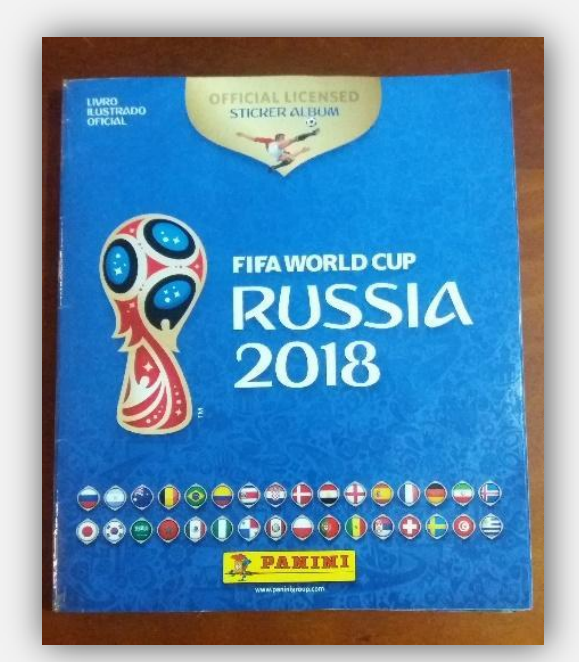

Fig. 1: Capa do álbum da Copa do Mundo de 2018.

Um dos componentes interessantes deste processo é que, a princípio, o álbum deveria funcionar como guia para o torcedor na Copa, mostrando a composição das seleções, tabela dos jogos e informações sobre os estádios. Quanto aos dois últimos itens, que são fixos e definidos com antecedência, o objeto cumpre seu papel. Mas a questão dos jogadores é mais complicada: como o produto é lançado cerca de três meses antes do início da competição, a produção do material é realizada antes da convocação daqueles atletas que, de fato, disputarão o evento por cada seleção.

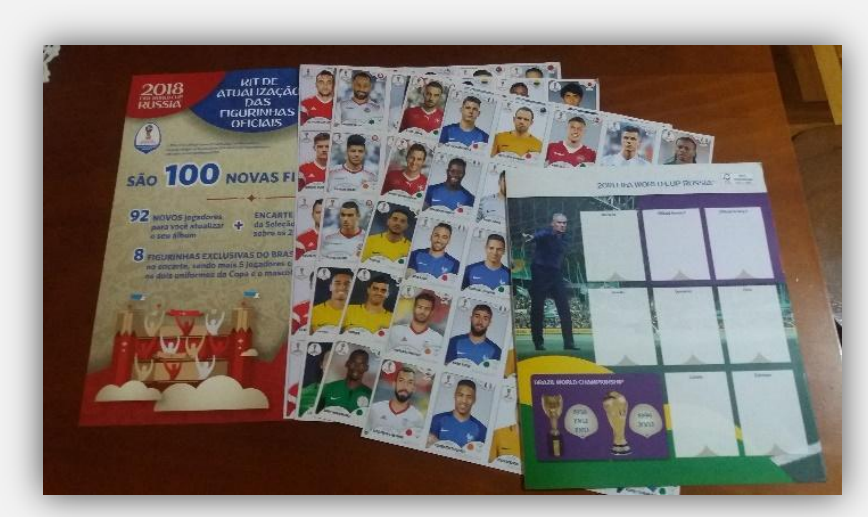

Fig. 2: Kit vendido durante a Copa do Mundo com atualização de figurinhas.

Deste modo, o álbum alimenta as especulações da mídia esportiva e dos fãs sobre quem serão os selecionáveis que estarão na competição, gerando polêmicas e repercussões quando as convocações de fato acontecem. Na edição de 2018, a Panini lançou uma atualização durante o evento, visando corrigir as falhas, ou seja, colocar os 
jogadores certos nas seleções. ${ }^{1}$ Por isso, justamente, a expressão "jogo dentro do jogo" como objeto de pesquisa: completar o álbum é um jogo e fazer as previsões dos jogadores convocados por cada país, outro jogo.

Mas de que jogo falamos? Seguimos, nesta pesquisa, os estudos sobre jogos de Huizinga ${ }^{2}$ e Roger Caillois, ${ }^{3}$ ambos pensadores que buscaram na filosofia reflexão sobre o papel central do jogo na cultura. ${ }^{4} 0$ primeiro chega ao ponto de dizer que essas atividades lúdicas apresentam "uma função significante". ${ }^{5}$

Campos (2014) comenta que

Entender a natureza do jogo no esporte é fundamental para entender a própria comunicação do mundo esportivo enquanto manifestação cultural, pois como Huizinga comenta, na prática esportiva do alto rendimento, 'o velho fator lúdico sofreu uma atrofia quase completa' (Huizinga, ibidem, p.220), rompendo com o descompromisso e com a falta de obrigação de produzir algo que há no lúdico. E essa atrofia, que passa pelo esporte profissional, terá nos megaeventos esportivos um novo momento. 6

É a partir dos megaeventos que o jogo enquanto texto da cultura irá se expandir para fora do território esportivo, construindo vinculações com o entretenimento e com o consumo. Afinal o álbum é sucesso de público e é bastante midiatizado, atraindo para a cultura esportiva do futebol o colecionismo inerente a outros universos. No jogo do álbum, o colecionador conquista seu "troféu" ao completar o álbum, independentemente dos resultados esportivos. Assim, não importa se a seleção do fã for desclassificada - um fracasso para o jogo como esporte -, pois ainda assim haverá uma satisfação com a realização pessoal de completar o livro.

Dentro da referida expansão para o universo do entretenimento e do consumo, na edição 2018 foram incorporadas alterações em relação à edição anterior da Copa de 2014, como a seção "Legends", que aumentou a quantidade de figurinhas metalizadas, talvez o maior "objeto de desejo" da edição de 2018. ${ }^{7}$ Foram alterados também os modos de interação do público com o material da Panini, com a criação do aplicativo

\footnotetext{
${ }^{1}$ Mesmo assim, as falhas continuam: o lateral-direito campeão pela França, Benjamin Pavard, foi eleito o autor do gol mais bonito na Copa, na partida das oitavas de final entre França e Argentina, mas a figurinha dele não consta do álbum original e nem da atualização vendida separadamente.

${ }^{2}$ HUIZINGA. Homo Ludens, 1996.

${ }^{3}$ CAILLOIS. Los juegos y los hombres, 1986.

${ }^{4}$ CAMPOS. A economia das imagens do esporte, p. 31-68.

${ }^{5}$ HUIZINGA. Homo Ludens, p. 4.

${ }^{6}$ CAMPOS. A economia das imagens do esporte, p. 33-34.

${ }^{7}$ In: http://bit.ly/2Fj9YZA.
} 
para acompanhamento da compra e troca dos cromos e o álbum virtual, diretamente relacionado ao físico por meio do QR Code de cada pacote de figurinhas.

As alterações do produto e das interações dele com os compradores são parte da análise aqui proposta. Por se tratar de um objeto cultural que alinha o futebol, símbolo do Brasil, ao colecionismo e ao modo de organização e de gestão dos megaeventos, o objeto se mostra rico e interessante para os estudos da comunicação e da cultura.

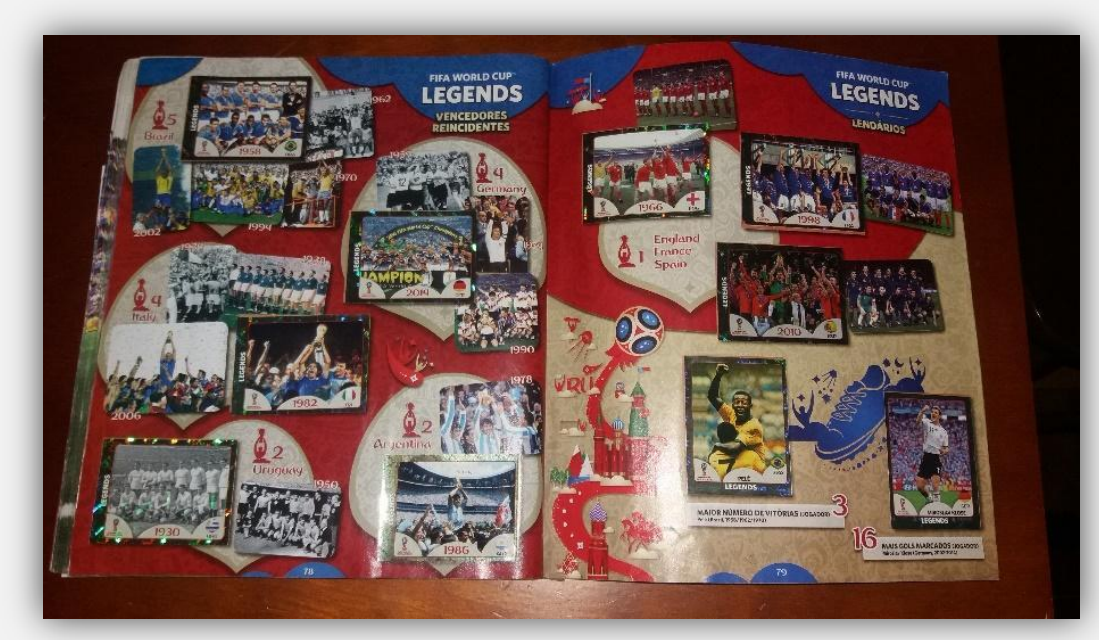

Fig. 3: Figurinhas lendárias, novidade criada para a Copa do Mundo de 2018.

Partimos neste estudo da semiótica da cultura russa, a partir de Lotman (1999), que estuda os textos resultantes dos sistemas da cultura, como o futebol, e as linguagens decorrentes deste processo. Tal fenômeno pode ser exemplificado na representação midiática do álbum de figurinhas da Copa do Mundo de 2018, mostrando como o sistema cultural futebol é capaz de criar novos textos da cultura além do esporte em si. Opta-se aqui pela observação dos processos comunicativos e de construção de imagens do megaevento esportivo referido no álbum de figurinhas e, por esta razão, não foram realizadas entrevistas com colecionadores, mas sim observados os mecanismos de mediação cultural estabelecidas pelo álbum como texto do sistema cultura futebol.

\section{O FUTEBOL COMO SISTEMA DA CULTURA}

Para a abordagem da semiótica, o futebol é um sistema no qual os componentes culturais interagem e nele predomina a tendência de modelos que são interdependentes 
a ponto de serem tomados como comportamento para a ação. ${ }^{8}$ Ou seja, dentro de um sistema com diversas fontes de atuação comunicacional, no futebol se destaca o padrão do esporte, que é modelizado por outros sistemas no processo de troca - caso da transmissão esportiva e dos produtos derivados do futebol, como o álbum de figurinhas, dentre muitos outros exemplos. Assim, a estruturação de seus códigos componentes - o próprio jogo, os atletas, a bola, os uniformes, os estádios, as tabelas, dentre outros - gera linguagens do sistema que são representadas na cultura por meio de textos, terminologia que pode ser equiparada ao conceito de signos na semiótica de Charles Sanders Peirce. Cada figurinha do álbum da Copa é um texto da cultura, assim como o próprio conjunto, o álbum, o é, em maior complexidade, sendo que todos esses textos são modelizados pela linguagem do colecionismo, do futebol e do megaevento.

Outra questão importante é lembrar, segundo Noth, ${ }^{9}$ que "no conceito de sistema está implicada a ideia de elementos que formam um todo ordenado e as relações entre esses elementos constituem a estrutura do sistema”. É justamente nesta relação entre os códigos, onde as linguagens são criadas e estruturadas, que precisamos colocar o funcionamento da modelização. Machado lembra que esse conceito foi forjado no campo da cibernética, designando a auto-organização das máquinas sem a qual não se processa a comunicação. "O campo da cultura passa a designar processos de regulação de comportamento de signos para constituir sistemas". Diante disso entende-se que a palavra 'modelização' deve ser entendida aqui como "um programa para análise e constituição de arranjos".10

Entendemos que o futebol utiliza os códigos do jogo para estruturar a linguagem do seu sistema. Tal codificação abre a oportunidade para explosões culturais que geram novas estratégias de comunicação advindas destas linguagens, assim como a criação de textos da cultura que se ressignificam continuamente, transformando-se em novos textos dentro do mesmo sistema. No futebol, o álbum de figurinhas pode ser a evocação inicial de um colecionismo até certo ponto ingênuo, baseado no companheirismo e em acordos entre amigos, mas que hoje pode movimentar transações comerciais, como, por exemplo, as figurinhas metálicas que se destacaram no álbum da Copa da Rússia de 2018.

Importante colocar que este tipo de ação, valorização de itens raros, faz parte do universo do colecionismo, bastante exemplificado pelas coleções filatélicas. Afinal,

\footnotetext{
${ }^{8}$ MACHADO. Escola de semiótica, p. 31.

${ }^{9}$ NOTH. Handbook of semiotics, p. 198.

${ }^{10}$ MACHADO. Escola de semiótica, p. 29.
} 
quanto mais um item é desejado por colecionadores, mais alto o valor de venda dele, tornando o objeto, em geral, caro e raro, ressignificando o valor simbólico a ele atribuído na cultura. Não é raro encontrar em mercados virtuais a venda de álbuns de antigos mundiais ou mesmo figurinhas de jogadores memoráveis a preços fora do padrão de mercado.

Tais processos de ressignificação fazem com que novos textos sejam tecidos pelos sistemas, justamente nos momentos de explosão da cultura - conceito discutido por Lotman ${ }^{11}$ em obra de mesmo nome e que se relaciona ao espaço semiótico ${ }^{12}$ formado pelos fragmentos de estruturas variadas, que conservam sua memória inicial mas, quando em choque uns com os outros, acabam por se configurar em novos textos.

No futebol, tal explosão se dá após movimentos de avanço, como aqueles de negociações milionárias de jogadores, quando os valores se tornam cada vez mais estratosféricos ${ }^{13} \mathrm{ou}$, ainda, quando uma regra tradicional sofre alteração, criando transformações que podem alterar o modo de funcionamento daquele mesmo jogo. Um exemplo é a utilização do $V A R^{14}$ pela FIFA a partir da Copa de 2018. Conferir lances polêmicos dos jogos com o uso do vídeo, que permite rever exaustivamente a jogada em dúvida, era algo solicitado por muitos e execrado por outros tantos. 0 uso oficial do VAR na Copa da Rússia já levou a discussões sobre como a ferramenta pode alterar o comportamento dos jogadores e o próprio modo de se jogar futebol. É justamente no momento da explosão que as trocas culturais ocorrem e que novos signos surgem, e tais trocas costumam ocorrer nos pontos de fronteira.

Para Lotman, nos mecanismos da cultura o conceito de fronteira no espaço semiótico é definido como uma "importantíssima posição funcional e estrutural que determina o mecanismo semiótico de dado sistema". ${ }^{15}$ É na fronteira, espaço de troca entre os sistemas da cultura, que novos textos surgem - caso do jogo modificado pelo árbitro de vídeo e do álbum de figurinhas, que vai sendo moldado e adequado ao novo

\footnotetext{
${ }_{11}^{11}$ LOTMAN. Cultura y explosión, 1999.

${ }^{12}$ Consideramos espaço semiótico como aquele onde ocorre o processo de semiose, ou seja, o processo de significação e a produção de significados, ou seja, a maneira como os seres humanos usam um signo, seu conteúdo e sua significação (MACHADO, 2003).

${ }^{13} \mathrm{O}$ jogador brasileiro Neymar Júnior foi comprado pelo time francês Paris Saint Germain em agosto de 2017 pelo valor recorde de $€ 220$ milhões, cerca de $R \$ 821$ milhões pelo câmbio daquela época, sendo a transação mais cara já realizada no futebol mundial.

${ }_{15}^{14}$ Sigla em inglês de Video Assistant Referee ou árbitro assistente de vídeo.

${ }^{15}$ LOTMAN. La semiosfera I, p. 196. (Nossa tradução).
} 
futebol. Tanto um quanto o outro precisam de inovações constantes para conseguirem se manter no "jogo" do consumo fugaz e rápido da contemporaneidade.

\section{ÁLBUM DE FIGURINHAS: TEXTO CULTURAL EM EVOLUÇão}

O álbum da Copa de 2018 conta com 682 figurinhas, sendo 50 metalizadas e 652 correspondem ao essencial do jogo: as fotos dos jogadores e estádios. Já, as 50 metalizadas correspondem aos escudos das seleções, troféu da Copa do Mundo, logotipo da FIFA e mascote da Copa. A novidade de 2018 foi a seção "Legends", localizada ao final do álbum, com imagens de todas as seleções vencedoras do torneio por ordem de quantidade de títulos. ${ }^{16}$ Figuram ali também a imagem de Pelé, como o jogador com o maior número de vitórias, três, e Miroslav Klose, como maior goleador, com 16 gols marcados entre as Copas de 2002 a 2014.

A seção "Legends" aumentou em dez figurinhas o número de cromos metálicos totais em relação ao álbum anterior, e estes cromos acabaram se tornando, de acordo com a mídia, a maior dificuldade dos colecionadores. Reportagem do HuffPost intitulada "Brilhantes que valem ouro: Figurinhas da Copa 2018 chegam a custar R\$ 7,00 no mercado 'paralelo'"17 mostra justamente essa questão da raridade das figurinhas, explicando porque alguns cromos inflacionaram o mercado de vendas entre colecionadores profissionais e amadores. Há casos citados neste mesmo texto de colecionadores que trocaram duas figurinhas brilhantes por 50 cromos dos jogadores.

É neste tipo de ação, típico do universo do colecionismo, que o álbum da Copa vai se configurando como jogo que movimenta outras esferas da cultura e do consumo. Um exemplo é o de locais não ligados originalmente ao ato de colecionar, tais como shoppings centers, serem levados a criar espaços para troca de figurinhas, incorporando práticas que são do jogo de colecionar e não do jogo futebol. Nas sociedades filatélicas, por exemplo, existem locais específicos e consagrados para trocas, reuniões e comercialização de itens de coleção, como os selos, condição que não se aplica originalmente para o álbum da Copa da Panini, por se tratar de objeto da cultura com

\footnotetext{
${ }^{16}$ Brasil com cinco títulos; Itália e Alemanha, quatro; Uruguai e Argentina, dois; Inglaterra, Espanha e França com um cada - na próxima edição a França passará para a categoria anterior, caso a seção seja mantida.

${ }_{17}$ In: http://bit.ly/2TGyQi5.
} 
período de duração comercial fugaz, mas que ganha alto poder de exposição midiática no contexto do jogo comercial e global do megaevento esportivo.

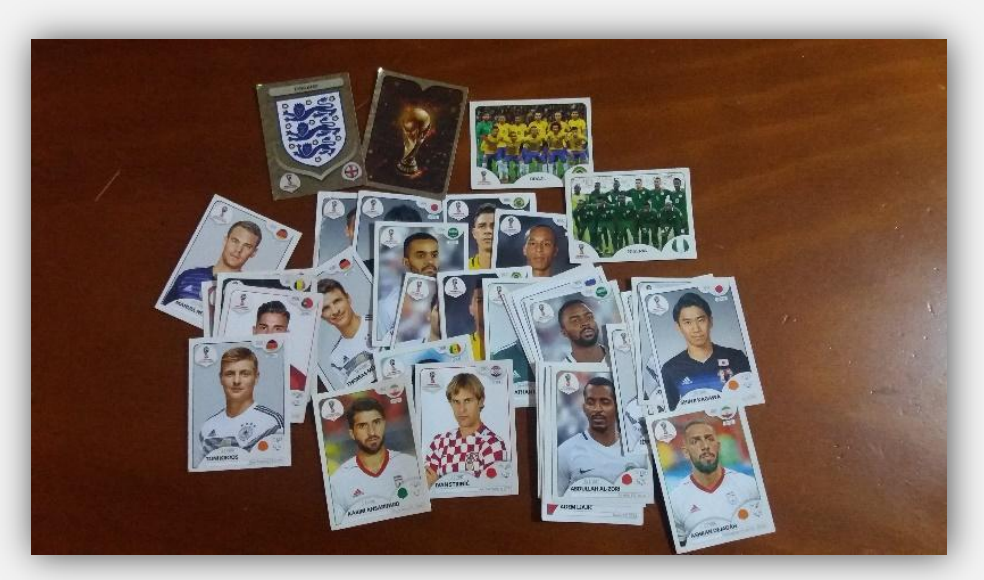

Fig. 4: Figurinhas "normais" e brilhantes: hierarquização de valor de troca e venda.

O cenário das figurinhas da Copa FIFA 2018 mostra a potência desse texto da cultura como elemento de explosão, ou seja, de intensa transformação. Assim é também porque qualquer texto precisa ser codificado (estruturado) duas vezes - pela língua natural e pela interação com outros sistemas, por exemplo - para que assim seja considerado:

O conceito de texto foi objeto de uma grande transformação. Os conceitos iniciais anulavam a natureza serial do texto, e também a unidade indivisível de suas funções dentro de um certo contexto cultural, ou qualquer outra qualidade que era pressuposta como implícita ao texto em um enunciado em qualquer língua. A primeira ideia deste conceito já se mostra logo generalista quando se examina o conceito de texto dentro da semiótica da cultura. Descobriu-se que, para uma dada mensagem ser definida como texto, ela deve estar codificada ao menos duas vezes. Assim, por exemplo, uma mensagem definida como lei se distingue da descrição de certo caso criminal porque pertence tanto ao sistema da língua natural na qual é escrita quanto aos sistemas da linguagem jurídica, constituindo no primeiro caso uma cadeia de signos com diversos significados e, no segundo, um signo complexo com um só significado. ${ }^{18}$

O álbum de figurinhas da Copa do Mundo 2018 foi traduzido para cada língua na qual foi lançado, embora o layout e a configuração do produto sejam quase padronizados, sofrendo poucas alterações de um lugar para o outro, pelas particularidades de interação com os textos da cultura do sistema futebol em cada país. Na reportagem "Brasil é o país que mais consome figurinhas do álbum da Copa da

${ }^{18}$ LOTMAN. La semiosfera I, p. 78. (Nossa tradução). 
Rússia",19 do jornal $O$ Estado de S. Paulo, a Panini afirma não divulgar números da operação, mas representantes da Panini afirmam que o consumo de cromos no Brasil é o dobro do montante consumido na Alemanha, segundo colocada no mercado de figurinhas da Copa do Mundo, sendo que foram feitas 92 edições em todo o mundo. Esse resultado coaduna com o fato de o Brasil ter a fama de ser o "país do futebol" e os brasileiros, para externarem essa paixão, fazem do mercado nacional o primeiro lugar no ranking de maiores consumidores do álbum, contribuindo para a dinâmica já antevista do jogo dentro do jogo.

Dentro do sistema cultural futebol existe a troca de fronteira com a linguagem dos megaeventos, estruturada em codificações de marketing e midiatização, por exemplo. Tal mecanismo obriga o álbum da Copa a ser cada vez mais espetacular e grandioso, criando um processo de ressignificação em importância para um público jovem e atento ao digital. Cabe analisar tanto a troca no espaço de fronteira do produto álbum da Copa com esse tipo de evento quanto com o próprio conceito de jogo, lembrando que completar todas as figurinhas, por mais difícil que seja, constitui um jogo que fascina os colecionadores, cria acordos comerciais e espaços novos, criando explosões e ressignificações culturais.

\section{OS MEGAEVENTOS ESPORTIVOS NA CULTURA DO FUTEBOL}

É a partir de Debord que inserimos nesta reflexão a teoria dos megaeventos esportivos. ${ }^{20}$ Se o "o espetáculo é uma relação social mediada por imagens",21 temos no contexto de atividades como a Copa do Mundo FIFA, os Jogos Olímpicos e algumas outras poucas atividades majoritárias que se impõem na indústria do entretenimento um exemplo cabal dessa ideia de que os espetáculos não são a representação dos acontecimentos de modo grandioso como costuma afirmar o senso comum, mas sim uma relação de mediação entre os acontecimentos e o mundo, transformando o comportamento humano mediante tais relações.

\footnotetext{
${ }^{19} \mathrm{http}: / /$ bit.ly/2VyrJtL.

${ }^{20}$ DEBORD. Sociedade do espetáculo, p. 14.

${ }^{21}$ Considerando o conceito da Tese 4 de Guy Debord em Sociedade do espetáculo (1997) de que o espetáculo é uma relação social mediada por imagens. Assim, o espetáculo se dá pela criação de imagens cada vez mais intrincadas em si, fazendo as pessoas mudarem laços sociais por causa delas, como o caso das figurinhas metalizadas citado anteriormente.
} 
Nos últimos anos vários teóricos debruçaram-se sobre a teoria dos megaeventos esportivos. Entre vários deles há a percepção que essas atividades envolvem grandes impactos econômicos, políticos e sociais, ${ }^{22}$ além de ter grande poder de agendamento midiático, quando fatos extraordinários (como exemplo, um Mundial de Futebol) ganham espaço e tempo extras na cobertura dos veículos de mídia. Contudo, Maurice Roche $^{23}$ é quem vai destacar o fato de que os megaeventos são atividades midiáticas, de grande poder de vinculação em escala planetária. Assim, podemos dizer que

\begin{abstract}
um megaevento pressupõe a existência de uma estrutura de tecnologia da informação e da comunicação (TIC) para que se realize. (...) Além disso, a construção de um ambiente midiático para que a comunidade global exista e assista ao espetáculo esportivo acaba proporcionando mídia para agentes do esporte e também para agentes terceiros que enxergamos esporte como excelente forma de levar suas mensagens ao público-final, o telespectador dos megaeventos. Tanto do ponto de vista infraestrutural quanto do conteúdo veiculado, os megaeventos são midiáticos já na sua constituição e as TICs são fundamentais para que eles ocorram. ${ }^{24}$
\end{abstract}

Contudo, os megaeventos se constituem como sistemas modelizantes que geram novos textos da cultura, dentro da codificação que os estrutura, a midiatização do esporte. Assim, a questão central dessa atividade estruturante é o jogo simbólico que acontece nela: a linguagem central dos megaeventos não é a do esporte, mas sim a das imagens do esporte. ${ }^{25}$ Sabendo-se que uma Copa do Mundo como a da Rússia 2018, por exemplo, cria um ambiente midiático que envolve muito mais pessoas do que aquelas que estiverem efetivamente nos locais oficiais de competição, o que se percebe é exatamente a construção de relações mediadas por imagens em essência.

Falar de megaeventos esportivos, do ponto de vista comunicacional, é falar das trocas econômico-simbólicas entre os esportes e toda a gama de agentes envolvidos no seu universo de constituição. É também falar de uma atividade supra-esportiva que, economicamente, acumula e gasta recursos relacionados ao mundo da prática desportiva profissional. Assim, todos os agentes e suas ações, inseridos nesse contexto, transformam-se em bens valoráveis e intercambiáveis em uma estratégia que tem como fim último a eficiência do megaevento em se tornar cada vez maior, midiática e economicamente falando. ${ }^{26}$

\footnotetext{
${ }^{22}$ CAMPOS. A economia das imagens do esporte, p. 133-144.

${ }^{23}$ ROCHE. Mega-events and Modernity, 2000.

${ }_{24}$ CAMPOS. A economia das imagens do esporte, p. 141.

${ }^{25}$ CAMPOS. A economia das imagens do esporte, $2014 \mathrm{a}$.

${ }^{26}$ CAMPOS. A Copa do Mundo como megaevento esportivo: afinal do que estamos falando? Uma abordagem comunicacional sobre a maior festa do futebol, p. 311-312.
} 
Sendo então o megaevento um aparelho, no sentido dado por Flusser,, ${ }^{27}$ vemos que esse megaevento subordina o público e não o contrário, como seria de se esperar. A cada edição da Copa, novas regras e restrições surgem e o público precisa se adaptar a elas. $\mathrm{Na}$ condição de aparelho flusseriano, joga-se o jogo do megaevento futebolístico, assim como se joga o jogo do álbum, tornando o ato de colecionar uma atividade à mercê dos interesses comerciais da editora, que muda o jogo a cada edição da Copa do Mundo.

Ainda no conceito de aparelho, as pessoas vinculadas ao megaevento atuam como funcionárias dele, retroalimentando o sistema nas suas várias frentes de atuação: sejam jogadores, técnicos, torcedores nos estádios, telespectadores espalhados ao redor do mundo e, já que falamos de imagens, empresas e suas marcas estrategicamente inseridas nessas construções imagéticas, inclusive no álbum da editora Panini. Em comum entre elas está o futebol, mas não aquele que é corpo em movimento e que está sendo testado nos limites das regras desse esporte: o que une todos esses agentesfuncionários do megaevento esportivo é a relação estabelecida por imagens a partir de um megaevento esportivo altamente midiatizado.

A Copa não dura apenas o mês em que o megaevento ocorre, mas, principalmente, o espaço de tempo entre uma edição e outra, no qual se insere a espera pelo álbum de figurinhas. Esta movimentação de jogo contínuo jogado em esferas comerciais, culturais, políticas, econômicas e do entretenimento, é possível pela retroalimentação do sistema, realizada pelos agentes que compõem a estrutura, por meio das imagens geradas e ou mediadas por eles: ora construindo o agendamento e a espera para a chegada das competições do megaevento; ora pertencendo ao megaevento durante a sua realização; ora partindo de imagens do megaevento realizado, projetando-as para o que está por vir.

Por isso, percebemos que a natureza do megaevento esportivo é converter a finitude e escassez do futebol, pois se trata de uma competição com começo, meio e fim demarcados e que é projetada em um novo jogo que não se esgota e que pode durar permanentemente no território das imagens - caso da coleção de figuras, que se mantém como um dos registros históricos do evento. Isso ocorre na fronteira entre o esporte e o

\footnotetext{
${ }^{27}$ FLUSSER. Filosofia da caixa preta, 1985.
} 
espetáculo, gerando o megaevento esportivo, que para realizar seu propósito "precisa expandir-se para as fronteiras do tempo e do espaço do esporte regular". 28

Se já explicitamos que os megaeventos estabelecem um ambiente midiático para trocas esportivas por meio de imagens, podemos inferir que os álbuns de figurinhas são, neste contexto, um texto da cultura a serviço dessa estratégia. Explicando o sucesso comercial dessa ação, os álbuns são, em essência, um jogo de manipular imagens, tal como a maioria dos objetos da mídia, que buscam criar vinculação com universos maiores - neste caso, com a realização da Copa do Mundo.

No conjunto, todos esses fatores contribuem para ver os megaeventos como mais que meros fatos noticiosos da pauta jornalística. Ou, ainda, se quisermos olhar por outro conceito tradicional: eles são mais que meros "agendadores" da pauta social. 0 que eles fazem é a midiatização do esporte, disseminando as imagens do esporte para ambientes muito além do espaço tradicional das disputas esportivas - e gerando, assim, os ambientes midiáticos dos megaeventos esportivos. ${ }^{29}$

No jogo dos megaeventos esportivos, o álbum de figurinhas configura-se então como uma estratégia de vinculação por imagens pré-evento esportivo, pois funciona como um convite para pertencer ao ambiente dessa competição ainda muito antes da realização dela. Contudo, ainda contribui para o sucesso do megaevento o fato de, num processo inverso, no jogo da manipulação (por aquisição e/ou troca) de imagens (figurinhas), o jogador constrói algo: o álbum. E com isso, ele materializa para si um "troféu", "um certificado de pertencimento ao esse clube", que é o grupo de quem tem o álbum completo.

O jogo torna-se ainda mais competitivo e, portanto, mais espetacular, pois é possível disputar para completar o álbum primeiro, o que já seria comum na esfera do colecionismo, mas há a espera para saber se as figurinhas realmente contemplarão as seleções, quais cromos serão realmente os mais difíceis de conseguir, se os jogadores de destaque do álbum serão, de fato, os melhores do evento. Assim, o colecionador se transforma em funcionário do aparelho, tal como mostrado por Flusser, pois ele se sente um jogador, mas que faz parte do jogo, traduzindo um status imagético que retroalimenta o espetáculo dos megaeventos esportivos.

\footnotetext{
${ }^{28}$ CAMPOS. A Copa do Mundo como megaevento esportivo: afinal do que estamos falando?, p. 312.

${ }^{29}$ CAMPOS. A Copa do Mundo como megaevento esportivo: afinal do que estamos falando?, p. 320-321.
} 


\section{LINGUAGEM DO JOGO: ÁLBUM E ESTRATÉGIAS COMUNICATIVAS}

Sendo o megaevento um sistema que compõe a semiosfera do futebol e, portanto, do esporte, a linguagem por ele gerada em objetos como o álbum de figurinhas configura um tipo de estratégia de comunicação associada à disputa pelo prêmio de quem venceu o desafio de ter todas as figurinhas - por mais difícil que seja, como em qualquer jogo de colecionismo.

Por isso nos referimos ao álbum como o "jogo dentro do jogo", aquele em que se joga a partir das regras de um sistema cultural com linguagem muito bem definida - o futebol -, mas que adquire vida própria criando outras estratégias próprias e novos textos culturais. Assim, a partir da necessidade do jogador que comprou o livro de completar as figurinhas, há uma série de estratégias que surgiram e foram sendo complexificadas para satisfazer esse jogo cada vez mais exigente.

A troca de cromos sempre existiu, especialmente como brincadeira de criança. 0 jogo do bafo, quando se batem as figurinhas com as mãos e aquelas que viram para cima passam a pertencer àquele que bateu, configura um jogo derivado desse grande jogo que é comprar o pacote de cromos e torcer para ter a sorte de conseguir não repetidos. No caso do livro da Copa, há o jogo de se enfrentar dificuldades que parecem cada vez mais complexas.

Lotman coloca a questão do desenvolvimento e complexidade dos textos da cultura em "Sobre o problema da tipologia da cultura", artigo da coletânea Semiótica Russa:

Todo o material da história da cultura pode ser examinado sob o ponto de vista de uma determinada informação de conteúdo e sob o ponto de vista do sistema de códigos sociais, os quais permitem expressar esta informação por meio de determinados signos e torná-la patrimônio desta ou aquelas coletividades humanas. ${ }^{30}$

A troca de figurinhas é um patrimônio dessa tradição do colecionismo, que vai se tornando expressão de coletividades inerentes ao contemporâneo. Hoje opera a intensa midiatização dos produtos da cultura, assim como o consumo exacerbado e as estratégias comunicativas de estímulo a essa realidade; o ato de completar precisa ser rápido, para fazer jus a um universo contemporâneo acelerado, estruturado pelo hiperconsumo. Lipovetsky aborda a questão, discutindo que buscamos hoje consumir tudo,

\footnotetext{
${ }^{30}$ LOTMAN. Sobre o problema da tipologia da cultura, p. 32.
} 
especialmente aquilo que nos torne especiais. ${ }^{31}$ Completar o álbum rápido é ser diferente, num cenário em que muitos fazem a coleção de figurinhas. Assim, quando todos querem ser diferentes acabam consumindo do mesmo modo e se tornando iguais a todos.

Abandonando o jogo inerente àquilo que podemos chamar de brincadeira, na Copa de 2018 intensificou-se a venda direta de cromos faltantes para os interessados. A negociação direta com a editora, quando se chega ao ponto da troca em que não se consegue ou não se quer mais batalhar por algumas figurinhas difíceis, é praxe desta prática, mas que se intensificou nesta última edição, com o surgimento da venda de cromos individuais tanto na internet quanto em pontos de venda físicos. Com preços sempre mais elevados do que o valor de $\mathrm{R} \$ 0,688$ que cada figurinha custava na Panini. ${ }^{32}$

Nessa linguagem do jogo dentro do álbum, o aparecimento de espaços próprios para troca de figurinhas, configurados não pelo interesse dos colecionadores, mas sim como fatores de atração criados pelos espaços de consumo, shoppings principalmente, mostram as estratégias de ludicização contínua do nosso cotidiano. Em troca com outro sistema cultural, o da publicidade, o futebol e o álbum geram novos textos culturais, que são as estratégias de publicização que tomam a Copa do Mundo emprestada e podem gerar ganhos comerciais e simbólicos para os estabelecimentos comerciais.

Estar atento ao desejo dos clientes de trocar figurinhas configura um grande apelo emocional, o que Lipovetsky e Serroy chamam de "advento de mercadorias mais impregnadas de dimensões simbólicas, de significados imaginários multiplicados; elas são menos um sinal de déficit de sentidos do que início da ludicização e da estetização do discurso comercial". ${ }^{33}$ Usando a brincadeira de troca de figurinhas, os shoppings atraíram o público para frequentar os espaços, gerando publicidade a custo baixo e expondo a sintonia das marcas com os desejos mais intensos dos fãs do megaevento ou, mesmo, com aqueles que apenas desejam estar inseridos no assunto do momento, aquele mais pautado pela mídia.

Outro destaque é a adequação da linguagem do jogo ao universo digital, com a criação dos aplicativos Panini para acompanhar o preenchimento do álbum e da versão virtual do livro. $\mathrm{O}$ aplicativo permite ao colecionador saber quais cromos ele já possui e

\footnotetext{
31 LIPOVETSKY. A felicidade paradoxal, 2006.

32 Pacotes com três cromos vendidos a $\mathrm{R} \$ 2,00$ na última edição - São Paulo: Cia das Letras, 2007.

33 LIPOVETSKY; SERROY. A estetização do mundo, p. 179.
} 
quais precisa adquirir e/ou trocar. Em plataforma simples, a interface funciona como um ponto de controle.

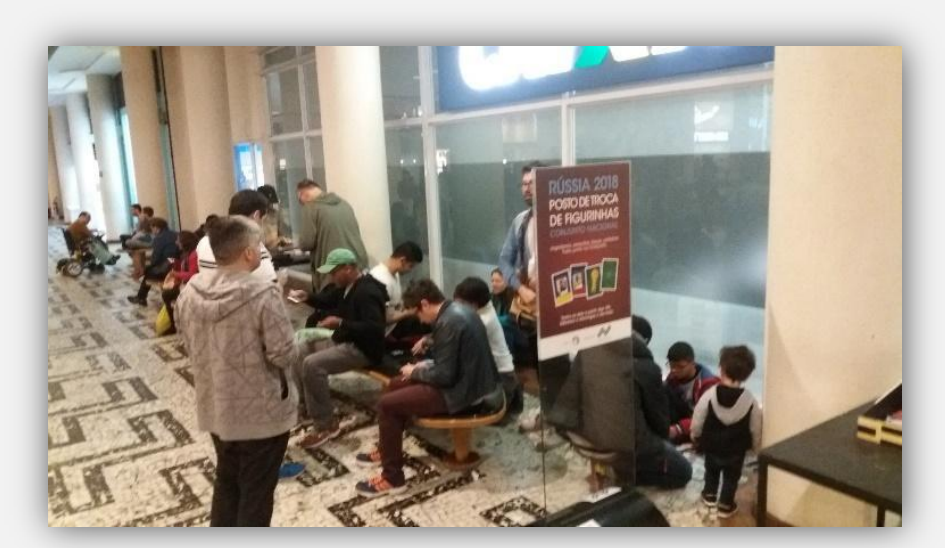

Fig. 5: Exemplo de espaço criado em centros comerciais e culturais para troca (e venda) de figurinhas entre fãs no Conjunto Nacional, na Avenida Paulista, em São Paulo.

Assim que o aplicativo do álbum virtual é baixado, se começa com cinco figurinhas e cinco novos pacotinhos são obtidos de tempos em tempos. Se o consumidor se cadastrar no site da Panini, ganha mais pacotes, e digitalizando o QR Code de cada pacote de figurinhas físicas, elas passam a fazer parte da versão virtual.

O álbum virtual se mostra como possível aposta no futuro do formato de álbum de figurinhas, criando novas possibilidades de se jogar dentro do jogo, quando o colecionador pode expor telas de seu progresso na aquisição de figurinhas nas redes sociais, por exemplo. Surgiria assim, uma nova faceta do jogo online, que pode derivar até para plataformas de videogames, por exemplo, em movimento a ser observado na próxima edição da Copa do Mundo.

Considerando que as fronteiras entre real e virtual são cada vez mais inexistentes, a troca de informações nessas fronteiras é intensa e constante, levando às explosões culturais contínuas. Naquele que Sodré chama de quarto bios, o biosmidiático, ${ }^{34}$ a mídia se incorpora à vida dos indivíduos de modo vital, fazendo parte do fluxo do cotidiano. Tal é o caso que já dava sinais nas trocas de informações nos grupos de Orkut dos álbuns das Copas de 2006 e 2010, páginas de Facebook, em 2010 e 2014, e, no caso em estudo aqui, em 2018, com o WhatsApp, Facebook e Instagram, principalmente, além das possibilidades de interação digital como o álbum virtual.

\footnotetext{
${ }^{34}$ SODRÉ. Antropológica do espelho, 2002.
} 
No contexto do biosmidático, a mídia não é objeto parte da vida, responsável por representar o cotidiano, mas a própria vida em si. Viver pelas telas dos celulares ou mesmo pelo aplicativo de troca de figurinhas ou pelas redes sociais onde se negocia a aquisição de objetos de coleção, além de acompanhar as movimentações de todos os colecionadores, é viver intensamente a vida pelo espetáculo, quando parece importar igual ou até mais a exposição nas redes das figurinhas que a aquisição delas. Essa visibilidade, que já observamos em outros cenários do consumo e entretenimento, como gastronomia e shows, também se mostra em passos acelerados no colecionismo.

Assim, comprar a figurinha física que incorpora o livro online, descobrir pelas redes sociais onde serão os eventos de troca ou mesmo fazer um post de apelo por ajuda para terminar o álbum configura uma constância cultural ressignificada no biosmidiático que não apresenta mais distinções de suporte. Esse cenário, que ilustra uma faceta do contemporâneo, ilumina também detalhes da relação do futebol na grandiosidade multifacetada dos megaeventos esportivos.

\section{CONSIDERAÇõES FINAIS}

$\mathrm{Na}$ vida que se estrutura e transcorre dentro e na cultura biosmidiática, as alterações observadas na edição de 2018 do álbum de figurinhas intensificam o sucesso deste texto da cultura, que opera como instrumento de vinculação aos megaeventos. Ao comprar o álbum e entrar neste jogo, os consumidores passam a pertencer também ao jogo do megaevento Copa do Mundo, construindo um vínculo intenso, que gera vários outros tipos de interação e participação nas estruturas do jogar esse jogo, por meio de imagens.

O objetivo costuma ser o de completar o álbum, período durante o qual se faz de tudo para terminá-lo: trocando, comprando, procurando figurinhas - o que, por sinal, é um fim para qualquer objeto do colecionismo. No caso da coleção de figurinhas ligada a um dos maiores eventos esportivos do mundo, a ansiedade para completar o álbum tem data: o período de realização da Copa, ao contrário de outras coleções, que não necessariamente precisam de um período de tempo determinado. Completar o álbum depois da competição faz com que a magia se perca, colocando este tipo de coleção num espaço tempo muito particular e tornando o processo de comunicação do fenômeno absolutamente particular e interessante para os estudos da área. 
Precisamos ponderar que há outro fenômeno a observar: alguns anos depois da ocorrência do megaevento, o álbum completo pode voltar a ter valor, tanto simbólico quanto comercial, sendo negociado como objeto histórico. Mas o fenômeno cultural mais intenso do ponto de vista da comunicação ocorre e demarca o período de realização da Copa do Mundo FIFA em que o álbum em montagem está vigente.

Quanto mais o público se interessa pelo álbum, mais as empresas também o fazem, reconfigurando a troca de figurinhas em eventos comerciais e não apenas lúdicos, e trazendo vários tipos de jogos para dentro do campo do jogo esportivo. Como patrocinar um megaevento é algo restrito a poucas e bilionárias empresas, aproveitar o tempo e o espaço da Copa do Mundo interessa e, assim, se configuram espaços comerciais de troca, tanto físicos quanto digitais. E levar tais espaços a serem vividos na fronteira entre o colecionismo tradicional, espaços de consumo e interesses dos megaeventos, tanto no suporte físico quanto digital, demonstra a explosão cultural identificada no biosmidiático que reconfigura mídia e vida muitas vezes, em sinônimos absolutos.

Concluímos ainda que, para manter o interesse do público a cada nova edição do álbum, é fundamental criar novas estratégias de vinculação ao megaevento, deixando o livro cada vez mais grandioso e jogando, assim, novos jogos de vinculação comunicacional com os públicos de interesse. Daí advém a seção "Legends" e, principalmente, o número aumentado de figurinhas brilhantes, que conduziram a busca pelas figurinhas a um estágio mais complicado, desempenhado em outras edições do álbum por cromos de jogadores famosos, por exemplo. Outra inovação é o álbum virtual, que acreditamos ter potencial de crescimento para a Copa do Qatar em 2022, além da atualização de figurinhas, que ganhou destaque comercial e midiático nesta edição.

Por fim, identificamos, no sistema cultural do futebol, o álbum de figurinhas da Panini como texto que não é novo, mas que vem sendo afetado pelos novos jogos midiáticos e comerciais jogados na fronteira entre o que há de mais ritualístico e tradicional com o que há de mais secular e mercantil no desporto. Metonimicamente, o álbum da Copa do Mundo da Rússia de 2018 comunica a natureza do próprio megaevento que cada vez mais converge o esporte com produção e manipulação da imagem, sendo cada vez maior o peso do jogo do espetáculo nessa composição. 


\section{Referências}

CAILLOIS, Roger. Los juegos y los hombres - la máscara y el vértigo. México: Fondo de Cultura Económica, 1986.

CAMPOS, Anderson Gurgel. A economia das imagens do esporte - produção, reprodução e valoração de bens imagéticos nos ambientes midiáticos dos megaeventos esportivos. Tese de Doutorado. São Paulo: PUC-SP, 2014a.

CAMPOS, Anderson Gurgel. A Copa do Mundo como megaevento esportivo: afinal do que estamos falando? Uma abordagem comunicacional sobre a maior festa do futebol. In:

São Paulo: Intercom, 2014b.

DEBORD, Guy. Sociedade do espetáculo. Rio de Janeiro: Contraponto Editora, 1997. FLUSSER, Vilém. Filosofia da caixa preta - ensaios para uma futura filosofia da fotografia. São Paulo: Hucitec, 1985.

HUIZINGA, Johan. Homo Ludens - o jogo como elemento da cultura. 4⿳亠丷a . Edição. São Paulo: Editora Perspectiva, 1996.

LIPOVETSKY, Gilles; SERROY, Jean. A estetização do mundo: viver na era do capitalismo artista. São Paulo: Cia das Letras, 2015.

LIPOVETSKY, Gilles. A felicidade paradoxal - ensaio sobre a sociedade do hiperconsumo. São Paulo: Cia das Letras, 2006.

LOTMAN, lúri. Cultura y explosión: lo previsible y lo imprevisible en los procesos de cambio social. Madrid: Gedisa Editorial, 1999.

LOTMAN, lúri. La semiosfera I - semiótica de la cultura y del texto. Madrid: Editora Cátedra, 1996.

LOTMAN, lúri. Sobre o problema da tipologia da cultura. In: SCHNAIDERMAN, Bóris. Semiótica Russa. São Paulo: Editora Perspectiva, 1979.

MACHADO, Irene. Escola de semiótica: a experiência de Tártu-Moscou para o estudo da cultura. São Paulo: Ateliê Editorial, 2003.

NOTH, Winfried. Handbook of Semiotics. Indiana: University Press, 1995.

ROCHE, Maurice. Mega-events and Modernity: Olympics and Expos in the Ground of Global Culture. London: Routledge, 2000.

SODRÉ, Muniz. Antropológica do espelho. Rio de Janeiro: Editora Vozes, 2002. 